\title{
The diagnostic ability of circulatory measurements from OCTA for glaucoma compared with structural measurements from OCT: A systematic review and meta-analysis
}

\author{
Qingyao Ning \\ The Second Affiliated Hospital, Zhejiang University School of Medicine \\ Jing Cao \\ The Second Affiliated Hospital, Zhejiang University School of Medicine \\ Lixia Lou \\ The Second Affiliated Hospital, Zhejiang University School of Medicine \\ Kai Jin \\ The Second Affiliated Hospital, Zhejiang University School of Medicine \\ Zhifang Liu \\ The Second Affiliated Hospital, Zhejiang University School of Medicine \\ Xizhe Dai \\ The Second Affiliated Hospital, Zhejiang University School of Medicine \\ Juan Ye ( $\square$ yejuan@zju.edu.cn ) \\ The Second Affiliated Hospital囚Zhejiang University School of Medicine https://orcid.org/0000-0002-5282-770X
}

\section{Research article}

Keywords: optic coherence tomography angiography, optic coherence tomography, glaucoma, vessel density, meta-analysis

Posted Date: May 26th, 2019

DOI: https://doi.org/10.21203/rs.2.9855/v1

License: (1) This work is licensed under a Creative Commons Attribution 4.0 International License. Read Full License 


\section{Abstract}

Background OCTA was a new non-invasive technique to detect blood perfusion in several layers of retina. This study aimed to evaluate the diagnostic advantages of OCTA circulatory parameters comparing with OCT structural parameters, and the diagnostic ability of the parameters between patients with normal tension glaucoma (NTG) and intraocular pressure (IOP) $>21 \mathrm{mmHg}$. Methods Four databases were searched (Pubmed, Cochrane Library, Web of Science, and EMBASE) for articles published up to Dec 2018. Pooled area under the receiver operating characteristic curve (AUROC) of OCTA and OCT parameters were used to perform the meta-analysis using Stata 15.0. The quality of included studies was accessed using the QUADAS-2 tool. Results Nine studies were selected from initial 1491 articles, involving 886 patients and more than 1149 eyes. Whole enface image vessel density (wiVD) (disc scan), ganglion cell complex (GCC) thickness and retinal nerve fiber layer (RNFL) showed the best AUROC, which was $0.93,0.94$ and 0.92 . Then followed by peripapillary VD (0.84), inside disc VD (0.84), wiVD (macular scan) (0.70), and parafoveal VD (0.65). Subgroup analysis showed AUROC of GCC and inside disc VD was 0.97 and 0.93 in the group with NTG, 0.92 and 0.77 in the group with IOP $>21 \mathrm{mmHg}$. Conclusion Structural parameters (RNFL and GCC) are wellbehaved in diagnosing all types glaucoma. WiVD (disc scan) represents good diagnostic accuracy of glaucoma comparable to structural parameters. Inside disc VD performed strong diagnostic ability for NTG patients.

\section{Introduction}

Glaucoma is the second cause of irreversible blindness worldwide. ${ }^{[1,2]}$ It affects more than 70 million people in the world and has been predicted to be over 100 million in 2040. ${ }^{[1,3]}$ However, glaucoma is undiagnosed in $90 \%$ affected people worldwide, and even in the developed countries $50 \%$ is undiagnosed. ${ }^{[4]}$

Glaucoma is a multifactorial optic neuropathy which is characterized by the death of retinal ganglion cells in the inner retina and loss of their axons in the optic nerve, thinning of the retinal nerve fiber layer (RNFL), cupping of the optic disc, and consequent visual field defects. $[5,6]$ The pathophysiology of glaucoma is still lack of fully understanding up to now. It was raised that intraocular pressure (IOP) was a trigger of glaucomatous changes. However, nearly $25-50 \%$ of glaucoma patients did not have elevated IOP, which indicates there might be other reasons leading to ganglion cells' death. ${ }^{[7-12]}$ One of the possible theory is the vascular etiology, which hypothesizes that vascular dysregulation such as vascular insufficiency plays an important role in the development and progression of glaucoma. ${ }^{[13-17]}$

Although the glaucomatous damage is irreversible, it could be prevented by early intervention. Therefore, an early diagnosis and close follow-up of glaucomatous patients is of critical importance. ${ }^{[6]}$ Optical coherence tomography (OCT) is a commonly used technology for glaucoma diagnosis and monitoring of disease progression, which could provide high-resolution cross-sectional images of ocular tissues such as optic nerve. It has been demonstrated that some OCT structural parameters like the thickness of RNFL and ganglion cell complex (GCC) showed good diagnostic accuracy to differentiate glaucoma patients from normal ones. ${ }^{[18,19]}$ Recently, a novel non-invasive technique, optical coherence tomography angiography (OCTA) has been introduced, which is able to detect vessel density (VD) and blood perfusion in various layers in the optic nerve head $(\mathrm{ONH})$, peripapillary and macular area. ${ }^{[18]}$ Numerous studies had reported the decrease of vessel density in different retinal regions of glaucomatous patients using OCTA. However, in which vascular parameters had better diagnostic ability for glaucoma and the comparison with the structural parameters, the results were varied due to many limitations. ${ }^{[11,19-26]}$ And little studies compared these parameters between glaucoma patients with normal IOP (normal tension glaucoma (NTG)) and those with high $\operatorname{IOP}(>21 \mathrm{mmHg})$.

In this study, we conducted a systematic review and meta-analysis to provide pooled estimates for the diagnostic ability of circulatory measurements from OCTA(including the vascular measurements of optic disc area, such as whole enface image vessel density (wiVD) (disc scan), peripapillary VD, inside disc VD, and those of macular area, such as parafoveal VD and wiVD (macular scan)) in glaucoma and subtypes of glaucoma, and to compare with the structural measurements from OCT (including RNFL and GCC thickness).

\section{Methods}

\section{Search Strategy}

We conducted a systematic search through four databases, including Pubmed (up to Dec 2018), Cochrane Library (up to Dec 2018), Web of Science (1900 to Dec 2018), EMBASE (1980 to Dec 2018), using the following search key terms: optical coherence tomography angiography, vessel density, glaucoma, primary open-angle glaucoma, primary angle-closed glaucoma and normal tension glaucoma. Search strategies are available in Additional file 1. There were no language restrictions of all literatures. The literatures were managed and duplicates were removed through Endnote X9 software. 
Two reviewers (QYN and JC) evaluated the retrieved articles after screening the titles and abstracts independently and excluded the ones that were obviously irrelevant. And then full texts of the remaining articles were read to determine whether they contained information on the topic of interest. References in the retrieved publications were checked for other pertinent studies.

\section{Study Selection}

The studies were included if they met the following criteria:

(1) The study was a cross-sectional study or cohort study.

(2) The study assessed the diagnostic accuracy of the OCTA and OCT parameters for glaucoma. The OCTA parameters included the wiVD (disc scan), peripapillary VD, inside disc VD, wiVD (macular scan) and parafoveal VD. And structural parameters measured by OCT referred to the thickness of RNFL or GCC.

(3) The study reported area under receiver operating characteristic curve (AUROC) statistics of the diagnostic parameters for glaucoma, and standard error(SE) or $95 \%$ confidence intervals(Cl) of AUROC.

(4) The study recruited patients with any classification of glaucoma, including NTG (IOP $\leq 21 \mathrm{mmHg}$ ), primary open angle glaucoma (POAG) and primary angel-closed glaucoma(PACG).

There are no limitations for the age or ethnic of participants. Studies would be removed if they are reviews, conference abstracts, letters or case reports, considering the lack of enough information. When different studies have overlapping participants, we select the one with more information.

\section{Data Extraction and Study Quality Evaluation}

Data for each eligible article were extracted as following by QYN and JC: (1) first author's name, year of publication, country; (2) type of OCTA system; (3) type of glaucoma; (4) design; (5) number of participants, number of eyes, age and gender; (6) AUROC (with SE or 95\% Cl).

The risk of bias and applicability of all included studies were assessed using the quality assessment of diagnostic accuracy studies, version 2(QUADAS-2), ${ }^{[25]}$ which comprises four domains: patient selection, index test, reference standard, and flow and timing. This was done by QYN and JC independently and discrepancy were finally resolved by senior author (JY).

\section{Statistical Analysis}

AUROC was frequently used to access diagnostic accuracy of OCTA and OCT parameters for glaucoma in recent studies. It's a common parameter that reflects both the sensitivity and specificity of a diagnostic test. It can be summarized over several studies when $\mathrm{SE}$ or $\mathrm{Cl}$ are provided and compared between different studies. ${ }^{[26]}$ Therefore, AUROC was selected for meta-analysis instead of other metrics such as sensitivity and specificity in our study.

Statistical analysis was performed using Stata (version 15.0; Stata Corp; College Station, Texas). The measurements of AUROC from each study were pooled into a weighted AUROC using the methods described by Zhou et al. ${ }^{[26]}$ Statistical heterogeneity among included studies was estimated by the $R$, chi-square test $\left(\chi^{2}\right)$, Cochran $Q$ and Z-valuestatistics. Significant heterogeneity was detected if $\mathrm{p}$ value was $<0.05$ or ${ }^{R}$ was $>50 \%$ and it supports the use of a random-effect model. Otherwise, a fixed-effect model was applied. Subgroup analysis would be conducted when heterogeneity was detected. The stability of results was tested by sensitivity analysis as following methods: (1) change of combination model, (2) removal of the article with the heaviest weight. Owing to the limited number of included articles, publication bias was not assessed. ${ }^{[27]}$

\section{Results}

\section{Selection and Characteristics of Eligible Studies}

After initial search and removal of duplicates, 1491 records were found. 1357 articles were excluded as irrelevant after undergoing title and abstract screening. The remaining 134 studies were evaluated with further full-text reading. 85 were excluded for inadequate parameters, 2 were editorial materials, 5 were conference abstracts, 27 were reviews, 6 lacked SE or Cl of AUROC. Finally, 9 articles were included for meta- 
analysis. ${ }^{[28-36]}$ The selection flow was shown in Fig 1. The main characteristics of the studies were summarized in Table 1. The eligible 9 studies, including 2 cohort studies and 7 cross-sectional studies, involved 886 patients and more than 1149 eyes. The mean age of glaucoma patients ranged from 53 to 72 years old, of control group was from 49 to 62 years old. One study was performed using Cirrus HDOCT (version 10.0.0.14618), the others was conducted by Optovue RTVue (AngioVue). One study recruited NTG patients, 2 selected PACG patients, and 7 included POAG patients. Five studies were conducted in India, 1 in America, 1 in Japan, 1 in China, and 1 in Russia.

\section{Study Quality Evaluation}

Methodological quality of included studies was assessed by QUADAS-2 and the quality scores were provided in Fig 2. In general, the quality of selected studies was high in terms of risk of bias and applicability. The main drawback was an unclear risk of bias in patient selection for 2 studies due to inadequate description of patient selection and exclusion methods, which was hard to be ascertained. Besides, 2 studies only recruited subjects with standard automated perimetry (SAP) abnormal visual fields, excluding preperimetric glaucoma patients.

\section{Diagnostic Accuracy of circulatory measurements from OCTA and structural measurements from OCT}

The diagnostic accuracy of OCT and OCTA parameters was listed in Table 2. Overall, wiVD (disc scan), GCC thickness and RNFL thickness showed the best AUROC of all parameters, which was 0.93 (95\% Cl: 0.90-0.95), 0.94 (95\% Cl: 0.92-0.97) and 0.92 (95\%Cl: 0.90-0.95), respectively. It indicated that the diagnostic ability of wiVD (disc scan) was comparable to the OCT structural parameters (GCC and RNFL thickness). Next were peripapillary VD of which AUROC was 0.84 ( $95 \% \mathrm{Cl}: 0.81-0.87$ ), and inside disc VD of which AUROC was 0.84 ( $95 \% \mathrm{Cl}$ : 0.80-0.88). The diagnostic accuracy of wiVD (macular scan) $(0.70$ (95\% Cl: $0.65-0.76))$ and parafoveal VD $(0.65(95 \% \mathrm{Cl}: 0.60-0.70))$ were lower than other parameters. A forest plot of diagnostic accuracy of OCT and OCTA parameters was shown in Fig 3a and Fig 3b, respectively. Besides, for the vascular parameters from OCTA, the measurements from optic disc area (such as wiVD (disc scan), peripapillary VD and inside disc VD) generally showed better diagnostic ability than those from macular area (such as wiVD (macular scan) and parafoveal VD).

\section{Heterogeneity Analysis And Subgroup Analysis}

No significant heterogeneity was found in RNFL thickness $\left(I^{2}=0.00 \%, P=0.484\right)$, wiVD (disc scan) $\left(I^{2}=11.80 \%, P=0.338\right.$ ), peripapillary VD ( $\left.{ }^{2}=0.00 \%, P=0.717\right)$, wiVD (macular scan) $\left(I^{2}=0.00 \%, P=0.85\right)$, and parafoveal VD $\left(I^{2}=0.00 \%, P=0.531\right)$. However, large heterogeneity was found in GCC $\left(1^{2}=53.00 \%, P=0.074\right)$ and inside disc VD $\left(I^{2}=76.80 \%, P=0.002\right)$, respectively. Therefore, subgroup analysis was conducted for inside disc VD and GCC according to the IOP: IOP $\leq 21 \mathrm{mmHg}$ (NTG group) and IOP>21 mmHg (POAG and PACG).

Subgroup analysis showed that, for NTG group, AUROC of inside disc VD $(0.93$ (95\% Cl: $0.86-1.00))$ was similar to that of GCC (0.97 (95\%Cl: 0.94-1.00)). For the high IOP (>21 mmHg) group, AUROC of GCC was $0.92(95 \% \mathrm{Cl}: 0.89-0.95)$ and of inside disc VD was 0.77 (95\%Cl: $0.72-$ 0.82), indicating that GCC thickness had a much better diagnostic accuracy than inside disc VD for POAG and PACG. The results were shown in Fig 4 and 5.

\section{Sensitivity analysis and publication bias}

Sensitivity analysis was performed by removing articles one at a time and detect the change of heterogeneity. For parafoveal VD, peripapillary VD, RNFL, peripapillary wiVD, and wiVD (macular scan), there were no significant changes with the methods described. As for GCC and inside disc VD, the heterogeneity became mild after removing the study by Takeyama et al ${ }_{1}^{[28]}$ with $\mathrm{I}^{2}$ decreasingfrom $50.00 \%$ to $0.00 \%$ and $76.80 \%$ to $0.00 \%$, respectively. Since the included studies in the report was less than 10 , publication bias was not accessed. [27]

\section{Discussion}

OCT has been one of the most important examination technologies in the diagnosis of glaucoma. With the development of OCTA, which could additionally provide vascular perfusion information of retinal structures, there has been a dispute on which parameters: structural or vascular parameters had better diagnostic ability for glaucoma for years. ${ }^{[37]}$

Previous studies suggested that OCT showed great diagnostic ability in all classifications of glaucoma by detecting peripapillary retinal nerve fiber layer and the macular ganglion cell layer ${ }^{[1,20]}$. It has been indicated that a substantial number of retinal ganglion cells (RGC) in 
the inner retina died and their axons in the optic nerve lost in glaucoma patients, which results in the decrease of RNFL thickness ${ }^{[5]}$. Since about $50 \%$ of all RGCs is in the macula, evaluating macular GCC using OCT becomes an effective method to assess RGC loss clinically. ${ }^{\text {[38] }}$ The diagnostic accuracy of GCC thickness was comparable to that of RNFL according to several studies. ${ }^{\text {[39-41] }}$ However, it was pointed out that there was a floor effect of OCT in advanced glaucoma which might limit its clinical application with increasingly severity of the disease. Rao et al. found that the peripapillary RNFL thickness showed little change in later stages of glaucoma, and the sensitivity of RNFL

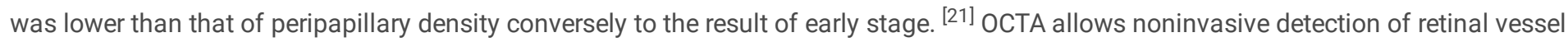
perfusion, which is closely related to glaucomatous severity. ${ }^{[42]}$ Several studies had compared the diagnostic ability between OCT and OCTA parameters. It was reported that AUROCs of peripapillary VD measurements were comparable to the corresponding RNFL thickness in both POAG and PACG. ${ }^{[21,43]}$ While Yarmohammadi et al. found that AUROC of peripapillary VD measurement was less than that of the RNFL thickness (0.83 vs. 0.92), but of wiVD (0.94) was higher than RNFL thickness, though without significant differences. ${ }^{[23]}$ In present study, for all kinds of glaucoma, we found only wiVD (disc scan) of OCTA exhibited similar diagnostic ability with structural parameters: GCC and RNFL thickness. This may attribute to the advantage of a larger measurement area, compared to the peripapillary VD. Besides, it has been showed that the reduced blood flow in the $\mathrm{ONH}$ was related to the morphology changes of ONH and increasing defect of visual field ${ }^{[44]}$, which is vital to the diagnosis and progress of glaucoma, resulting in the high AUROC of wiVD (disc scan).

Besides, we found that circulatory measurements from optic disc area showed better diagnostic ability than those from macular area. There were studies reporting that macula vessel density had significantly lower diagnostic abilities in POAG than the peripapillary density. ${ }^{[34,36]}$ However, it was pointed out that macular superficial vessel density had similar diagnostic accuracy to RNFL and GCC thickness for differentiating between glaucomatous and healthy eyes in early stage of glaucoma. ${ }^{[45]}$ One possible explanation may be that the retinal vessels in macular area are the terminal of retinal branches. These vessels decrease significantly during the early stage of glaucoma but reach the floor in the late stage of glaucoma. Considering that most of our included studies contains patients not only in the early stage, but also with severe glaucoma, the pooled vascular measurements of macular area might be lower than that for early stage of glaucoma. It also suggests that the macular vessel density is not a generally compatible parameter for all types or stages of glaucoma.

Subgroup analysis showed that for NTG group, GCC, inside disc VD, wiVD (disc scan) and RNFL performed strong diagnostic ability. However, for the high IOP group, the diagnostic ability of inside disc VD was significantly lower than the other three parameters. It might indicate the different physiopathological mechanisms of ONH perfusion and structural changes in different types of glaucoma. Previous study found that ONH VD had significant correlation with baseline IOP in POAG. ${ }^{[34]}$ This suggested that the vascular mechanisms contributing to the pathogenesis of glaucoma are not IOP-independent. On the contrary, the IOP-independent factors may play a more important role in the development of NTG, such as vascular factors which lead to the changes of inside disc vessel density. In 1858, von Jaeger came up with the theory that the optic nerve damage was due to ischemia instead of mechanical compression of the optic nerve fibers. ${ }^{[46]}$ Several studies also showed that decreased blood supply could lead to the degeneration of ganglion cells in NTG but less involved in the deterioration in glaucomatous patients with increased IOP. ${ }^{[47-50]}$ The damage to optic nerves could be caused by chronic ischemia and reperfusion. ${ }^{[51]}$ However, it's still not clear whether the VD change and insufficient blood flow is the cause or the consequence of optic nerve changes and more experiments are needed.

There were several limitations in our meta-analysis that could not be ignored. Firstly, we only included nine studies to analyze the diagnostic ability of OCTA parameters and consequently, the publication bias could not be accessed. Secondly, the differences between different OCTA systems could not be avoided and it might bring about the measurement bias among different studies. Thirdly, there were limited numbers of studies in the subgroup analyses. Studies reported different parameters such as GCC, RNFL, inside disc VD. Hence, we had to separate all types of parameters and reduce the sample size of studies, which might decrease the stability of AUROC estimates. Finally, all studies were performed when the patients were already diagnosed as glaucoma, which was different from the real clinical scenes when patients are not differentiated.

\section{Conclusions}

OCT structural parameters like GCC and RNFL thickness are well-behaved in diagnosing all types of glaucoma. For circulatory measurements of OCTA, wiVD (disc scan) represents good diagnostic accuracy of glaucoma, which is similar to that of GCC and RNFL thickness. Inside disc VD performed a comparable diagnostic ability with structural parameters for glaucomatous patients with NTG.

Besides, vascular measurements from optic disc area represented better diagnostic capacity than that from macular area. However, studies with larger sample and high quality estimating the function of OCTA in different classifications of glaucoma are still urgently warranted.

\section{List Of Abbreviations}


RNFL: nerve fiber layer

IOP: intraocular pressure

OCT: Optical coherence tomography

GCC: ganglion cell complex

OCTA: optical coherence tomography angiography

VD: vessel density

ONH: optic nerve head

NTG: normal tension glaucoma

wiVD: whole enface image vessel density

AUROC: area under receiver operating characteristic curve

SE: standard error

$\mathrm{Cl}$ : confidence intervals

POAG: primary open angle glaucoma

PACG: primary angel-closed glaucoma

QUADAS-2: quality assessment of diagnostic accuracy studies, version 2

SAP: standard automated perimetry

RGC: retinal ganglion cells

\section{Declaration}

\section{Acknowledgements}

This study was funded by National Natural Science Foundation of China (No. 81670888). The funders played no role in study design, data collection and analysis, or writing the manuscript

\section{Funding}

This study was funded by National Natural Science Foundation of China (No. 81670888).

\section{Availability of data and materials}

All data extracted or analysed during this study are included in this article and its supplementary information files.

\section{Authors' contributions}

All authors have made substantive intellectual contributions to this study. Qingyao Ning and Jing Cao evaluated the related articles, extract data from each eligible article, conducted statistical analysis and prepared daft manuscript. Kai Jin and Lixia Lou contributed to the design of this work. Zhifang Liu and Xizhe Dai screened related articles. Discrepancy were finally resolved by Juan Ye. All authors reviewed and approved the final version of the manuscript. 
Not applicable.

\section{Consent for publication}

Not applicable.

\section{Conflict of Interest}

The authors declare that they have no conflict of interest.

\section{References}

1. Tham Y-C, Li X, Wong TY, Quigley HA, Aung T, Cheng C-Y. Global prevalence of glaucoma and projections of glaucoma burden through 2040. Ophthalmology.2014; 121: 2081-2090.

2. Kingman S. Glaucoma is second leading cause of blindness globally. Bull World Health Organ. 2004; 82:887

3. Weinreb RN, Aung T, Medeiros FA. The pathophysiology and treatment of glaucoma: a review. Jama. 2014; 311:1901-11.

4. Quigley HA. Broman A. The number of persons with glaucoma worldwide in 2010 and 2020.Br J Ophthalmol. 2006; 90: $151-156$.

5. Quigley HA. Glaucoma. The Lancet. 2011; 377: 1367-1377.

6. Jonas JB, Aung T, Bourne RR, Bron AM, Ritch R, Panda-Jonas S. Glaucoma. The Lancet. 2017; 390: $2183-2193$.

7. Kass, M.A., Heuer, D.K., Higginbotham, E.J. et al. The Ocular Hypertension Treatment Study: a randomized trial determines that topical ocular hypotensive medication delays or prevents the onset of primary open-angle glaucoma. Arch Ophthalmol. 2002; 120: 701-713

8. Aung, T., Ocaka, L., Ebenezer, N.D. et al. A major marker for normal tension glaucoma: association with polymorphisms in the OPA1 gene. Hum Genet. 2002; 110: 52-56

9. Grus, F.H., Joachim, S.C., and Pfeiffer, N. Analysis of complex autoantibody repertoires by surface-enhanced laser desorption/ionizationtime of flight mass spectrometry. Proteomics. 2003; 3: 957-961

10. Burgoyne, C.F. A biomechanical paradigm for axonal insult within the optic nerve head in aging and glaucoma. Exp Eye Res.2010; 93 : $120-132$

11. Maruyama, I., Ikeda, Y., Nakazawa, M., and Ohguro, H. Clinical roles of serum autoantibody against neuron-specific enolase in glaucoma patients. Tohoku J Exp Med. 2002; 197: 125-132

12. Nickells, R.W., Howell, G.R., Soto, I., and John, S.W. Under pressure: cellular and molecular responses during glaucoma, a common neurodegeneration with axonopathy. Annu Rev Neurosci. 2012; 35: 153-179

13. Yanagi M, Kawasaki R, Wang JJ, Wong TY, Crowston J, Kiuchi Y. Vascular risk factors in glaucoma: A review. Clin Exp Ophthalmol. 2011; 39:252-258.

14. Nicolela MT. Clinical clues of vascular dysregulation and its association with glaucoma. Can J Ophthalmol. $2008 ; 43: 337-341$.

15. Ster AM, Popp RA, Petrisor FM, Stan C, Pop VI. The Role of Oxidative Stress and Vascular Insufficiency in Primary Open Angle Glaucoma. Clujul Med. 2014; 87:143-146.

16. Pasquale LR. Vascular and autonomic dysregulation in primary open-angle glaucoma. Curr Opin Ophthalmol. 2016; 27:94-101.

17. Flammer J, Orgul S, Costa VP, et al. The impact of ocular blood flow in glaucoma. Prog Retin Eye Res. 2002; 21:359-393.

18. Chung JK, Hwang YH, Wi JM, Kim M, Jung JJ. Glaucoma Diagnostic Ability of the Optical Coherence Tomography Angiography Vessel Density Parameters. Current eye research. 2017; 42:1458-1467. 
19. Kansal V, Armstrong JJ, Pintwala R, Hutnik C. Optical coherence tomography for glaucoma diagnosis: An evidence based meta-analysis. PloS one. 2018; 13: e0190621.

20. Wang M, Lu AT, Varma R, Schuman JS, Greenfield DS, Huang D. Combining information from 3 anatomic regions in the diagnosis of glaucoma with time-domain optical coherence tomography. J Glaucoma.2014; 129-135.

21. Rao HL, Pradhan ZS, Weinreb RN, et al. Vessel density and structural measurements of optical coherence tomography in primary angle closure and primary angle closure glaucoma.Am J Ophthalmol 2017; 177: 106-115.

22. Van Melkebeke L, Barbosa-Breda J, Huygens M, Stalmans I. Optical Coherence Tomography Angiography in Glaucoma: A Review. Ophthalmic research 2018; 1-13.

23. Triolo G, Rabiolo A, Shemonski ND, et al. Optical Coherence Tomography Angiography Macular and Peripapillary Vessel Perfusion Density in Healthy Subjects, Glaucoma Suspects, and Glaucoma Patients. Investigative ophthalmology \& visual science. 2017; 58:57135722.

24. Wan KH, Lam AKN, Leung CK. Optical Coherence Tomography Angiography Compared With Optical Coherence Tomography Macular Measurements for Detection of Glaucoma. JAMA. Ophthalmology.2018; 136(8):866-874..

25. Whiting PF, Rutjes AWS, Westwood ME, Mallett S, Deeks JJ, Reitsma JB, et al. QUADAS-2: a revised tool for the quality assessment of diagnostic accuracy studies. Ann Intern Med. 2011;155: 529-536.

26. Zhou X-H, McClish DK, Obuchowski NA. Statistical methods in diagnostic medicine. New York: John Wiley \& Sons, Ltd.2009

27. Higgins JPT, Green S (editors). Cochrane Handbook for Systematic Reviews of Interventions Version 5.1.0 [updated March 2011]. The Cochrane Collaboration, 2011.

28. Takeyama A, Ishida K, Anraku A, Ishida M, Tomita G. Comparison of Optical Coherence Tomography Angiography and Laser Speckle Flowgraphy for the Diagnosis of Normal-Tension Glaucoma. Journal of ophthalmology. 2018:1751857.

29. Rao HL, Riyazuddin M, Dasari S, et al. Diagnostic Abilities of the Optical Microangiography Parameters of the 3x3mm and $6 \times 6 \mathrm{~mm}$ Macular Scans in Glaucoma. Journal of glaucoma.2018

30. Rao HL, Kadambi SV, Weinreb RN, et al. Diagnostic ability of peripapillary vessel density measurements of optical coherence tomography angiography in primary open-angle and angle-closure glaucoma. The British journal of ophthalmology. 2017; 101:1066-1070.

31. Chen HS, Liu CH, Wu WC, Tseng HJ, Lee YS. Optical Coherence Tomography Angiography of the Superficial Microvasculature in the Macular and Peripapillary Areas in Glaucomatous and Healthy Eyes. Investigative ophthalmology \& visual science. 2017; 58:3637-3645.

32. Yarmohammadi A, Zangwill LM, Diniz-Filho A, et al. Optical Coherence Tomography Angiography Vessel Density in Healthy, Glaucoma Suspect, and Glaucoma Eyes. Investigative ophthalmology \& visual science .2016; 57: OCT451-9.

33. Rao HL, Pradhan ZS, Weinreb RN, et al. Optical Coherence Tomography Angiography Vessel Density Measurements in Eyes With Primary Open-Angle Glaucoma and Disc Hemorrhage. Journal of glaucoma. 2017; 26:888-895.

34. Rao HL, Pradhan ZS, Weinreb RN, et al. Regional Comparisons of Optical Coherence Tomography Angiography Vessel Density in Primary Open-Angle Glaucoma. American journal of ophthalmology. 2016; 171:75-83.

35. Rao HL, Pradhan ZS, Weinreb RN, et al. Vessel Density and Structural Measurements of Optical Coherence Tomography in Primary Angle Closure and Primary Angle Closure Glaucoma. American journal of ophthalmology.2017; 177:106-115.

36. Kurysheva NI, Maslova EV, Zolnikova IV, Fomin AV, Lagutin MB. A comparative study of structural, functional and circulatory parameters in glaucoma diagnostics. PLoS One. 2018;13(8):21..

37. Hood DC, Anderson SC, Wall M, Kardon RH, Raza AS. A test of a linear model of glaucomatous structure-function loss reveals sources of variability in retinal nerve fiber and visual field measurement. Investigative Ophthalmology \& Visual Science. $2009 ; 50: 4254-4255$.

38. Jeoung JW, Choi YJ, Park KH, Kim DM. Macular ganglion cell imaging study: glaucoma diagnostic accuracy of spectral-domain optical coherence tomography. Invest Ophthalmol Vis Sci. 2013; 54: 4422-4429. 
39. Mwanza JC, Durbin MK, Budenz DL, et al. Glaucoma diagnostic accuracy of ganglion cell-inner plexiform layer thickness: comparison with nerve fiber layer and optic nerve head. Ophthalmology. 2012; 119: 1151-1158.

40. Kim HJ, Lee SY, Park KH, Kim DM, Jeoung JW. Glaucoma diagnostic ability of layer-by-layer segmented ganglion cell complex by spectral-domain optical coherence tomography. Invest Ophthalmol Vis Sci. 2016; 57: 4799-4805. 7.

41. Garas A, Vargha P, Hollo G. Diagnostic accuracy of nerve fibre layer, macular thickness and optic disc measurements made with the RTVue-100 optical coherence tomograph to detect glaucoma. Eye. 2011; 25: 57-65.

42. Wang X, Jiang C, Ko T, et al. Correlation between optic disc perfusion and glaucomatous severity in patients with open-angle glaucoma: an optical coherence tomography angiography study. Graefe's archive for clinical and experimental ophthalmology. 2015; 253:1557-64.

43. Chung JK, Hwang YH, Wi JM, Kim M, Jung JJ. Glaucoma Diagnostic Ability of the Optical Coherence Tomography Angiography Vessel Density Parameters. Current eye research. 2017; 42:1458-1467.

44. Resch H, Schmidl D, Hommer A, et al. Correlation of optic disc morphology and ocular perfusion parameters in patients with primary open angle glaucoma. Acta ophthalmologica. 2011; 89: e544-9.

45.Chen HSL, Liu CH, Wu WC, et al. Optical coherence tomography angiography of the superficial microvasculature in the macular and peripapillary areas in glaucomatous and healthy eyes. Invest Ophthalmol Vis Sci. 2017; 58: 3637-3645.

46.Jaeger E. Über Glaukom und seine Heilung durch Iridektomie. Z Ges Aerzte Wein. 1858: 14: 465-91.

47. Yamazaki Y, Drance SM. The relationship between progression of visual field defects and retrobulbar circulation in patients with glaucoma. Am J Ophthalmol. 1997; 124:287-95.

48. Katai N, Yoshimura N. Apoptotic retinal neuronal death by ischemia-reperfusion is executed by two distinct caspase family proteases. Invest Ophthalmol Vis Sci. 1999; 40:2697-705.

49. Cioffı GA, Sullivan P. The effect of chronic ischemia on the primate optic nerve. Eur J Ophthalmol.1999; 9: S34-6.

50. Killer HE, Pircher A. Normal tension glaucoma: review of current understanding and mechanisms of the pathogenesis. Eye. 2018; 32:924930.

51. Flammer J, Orgul S, Costa VP, et al. The impact of ocular blood flow in glaucoma. Prog Retin Eye Res. 2002; 21:359-93.

\section{Tables}

\section{Table 1 Characteristics of the included studies in the meta-analysis}




\begin{tabular}{|c|c|c|c|c|c|c|c|c|c|c|c|c|c|}
\hline \multirow[t]{2}{*}{ Author } & \multirow[t]{2}{*}{ Year } & \multirow[t]{2}{*}{ Country } & \multirow[t]{2}{*}{ OCTA } & \multirow[t]{2}{*}{ Glaucoma } & \multirow[b]{2}{*}{ Design } & \multicolumn{2}{|c|}{$\begin{array}{c}\text { Number of } \\
\text { subjects }\end{array}$} & \multicolumn{2}{|c|}{$\begin{array}{c}\text { Number of } \\
\text { eyes }\end{array}$} & \multicolumn{2}{|c|}{ Mean age (year) } & \multicolumn{2}{|c|}{ Sex ratio $[M / F \square$} \\
\hline & & & & & & case & control & case & control & case & control & Case & Control \\
\hline $\begin{array}{l}\text { Takeyama, A et } \\
\text { al. }\end{array}$ & 2018 & Japan & Optovue & $\mathrm{NTG}^{\mathrm{a}}$ & $\begin{array}{l}\text { cohort } \\
\text { studies }\end{array}$ & 28 & 25 & 28 & 25 & $53.7 \pm 12.2$ & $49.3 \pm 10.0$ & $13: 15$ & $14: 11$ \\
\hline Rao, H. L. et al. & 2018 & India & Cirrus & $\mathrm{POAG}^{\mathrm{b}}$ & $\begin{array}{c}\text { cross- } \\
\text { sectional } \\
\text { study }\end{array}$ & 57 & 57 & 88 & 96 & $\begin{array}{c}59.6 \pm \\
11.8\end{array}$ & $\begin{array}{c}55.2 \pm \\
12.3\end{array}$ & $40: 17$ & $30: 27$ \\
\hline Rao, H. L. et al. & 2017 & India & Optovue & POAG/PACG ${ }^{\mathrm{C}}$ & $\begin{array}{l}\text { cross- } \\
\text { sectional } \\
\text { study }\end{array}$ & 71 & 33 & 112 & 48 & $\begin{array}{c}64.55 \pm \\
15.02\end{array}$ & $\begin{array}{c}52 \pm \\
23.58\end{array}$ & $39: 32$ & $39: 32$ \\
\hline $\begin{array}{l}\text { Chen, H. S. et } \\
\text { al. }\end{array}$ & 2017 & Taiwan & Optovue & POAG & $\begin{array}{c}\text { cross- } \\
\text { sectional } \\
\text { study }\end{array}$ & 26 & 27 & 26 & 27 & $57 \pm 13$ & $57 \pm 12$ & $14: 12$ & $15: 12$ \\
\hline $\begin{array}{l}\text { Yarmohammadi, } \\
\text { A. et al. }\end{array}$ & 2016 & America & Optovue & POAG & $\begin{array}{l}\text { cohort } \\
\text { studies }\end{array}$ & 104 & 23 & $\mathrm{NA}^{\mathrm{d}}$ & NA & $\begin{array}{l}72.4 \pm \\
41.39\end{array}$ & $\begin{array}{c}53.5 \pm \\
14.34\end{array}$ & $55: 49$ & $14: 9$ \\
\hline Rao, H. L. et al. & 2017 & India & Optovue & POAG & $\begin{array}{c}\text { cross- } \\
\text { sectional } \\
\text { study }\end{array}$ & 76 & 46 & 97 & 66 & $\begin{array}{c}65.83 \pm \\
19.23\end{array}$ & $\begin{array}{l}59.7 \pm \\
21.05\end{array}$ & $41: 35$ & $25: 21$ \\
\hline Rao, H. L. et al. & 2016 & India & Optovue & POAG & $\begin{array}{c}\text { cross- } \\
\text { sectional } \\
\text { study }\end{array}$ & 39 & 53 & 64 & 78 & $\begin{array}{c}66 \pm \\
30.85\end{array}$ & $\begin{array}{c}58 \pm \\
23.58\end{array}$ & $28: 11$ & $29: 24$ \\
\hline Rao, H. L. et al. & 2017 & India & Optovue & PACG & $\begin{array}{c}\text { cross- } \\
\text { sectional } \\
\text { study }\end{array}$ & 46 & 50 & 65 & 77 & $62.0 \pm 7.8$ & $60.7 \pm 8.3$ & $25: 21$ & $27: 23$ \\
\hline $\begin{array}{l}\text { Kurysheva, NI. } \\
\text { et al }\end{array}$ & 2018 & Russia & Optovue & POAG & $\begin{array}{c}\text { cross- } \\
\text { sectional } \\
\text { study }\end{array}$ & 90 & 35 & 90 & 35 & $64.4 \pm 6.7$ & $62.4 \pm 5.5$ & NA & NA \\
\hline
\end{tabular}

a. NTG: normal tension glaucoma

b. POAG: primary open angle glaucoma

c. PACG: primary angle-closed glaucoma

d. NA: not available

Table 2

Comparison of parameters using the Pooled AUROC

\begin{tabular}{lll}
\hline & AUC & 95\%CI \\
\hline Parafoveal VD & 0.65 & $0.60-0.70$ \\
wiVD(macular scan)* & 0.70 & $0.65-0.76$ \\
\hline Inside disc VD** & 0.84 & $0.80-0.88$ \\
\hline IOP $\leq 21 \mathrm{mmHg}$ & 0.93 & $0.87-1.00$ \\
\hline IOP $>21 \mathrm{mmHg}$ & 0.77 & $0.72-0.82$ \\
\hline Peripapillary VD & 0.84 & $0.81-0.87$ \\
\hline wiVD (dosc scan) & 0.93 & $0.90-0.95$ \\
\hline RNFL*** & 0.92 & $0.90-0.95$ \\
\hline GCC**** & 0.94 & $0.92-0.97$ \\
\hline IOP $\leq 21 \mathrm{mmHg}$ & 0.97 & $0.94-1.00$ \\
\hline IOP>21 mmHg & 0.92 & $0.89-0.95$ \\
\hline
\end{tabular}

*. wiVD: whole enface image vessel density

**. VD: vessel density

***. RNFL: retina nerve fiber layer

****. GCC: ganglion cell complex

\section{Additional File Legend}

Additional file 1: Search strategy

Figures 


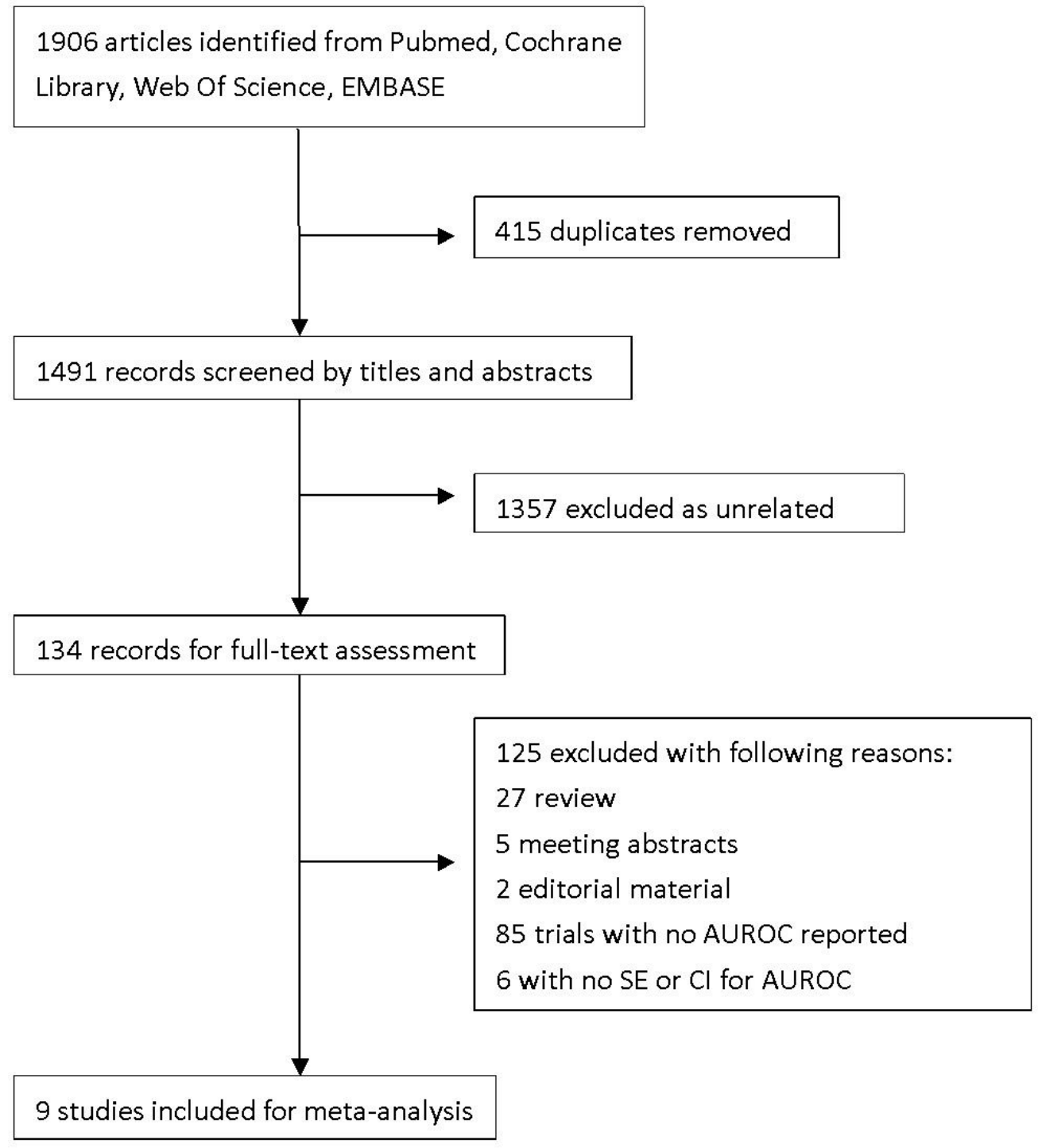

Figure 1

Flowchart of study selection.

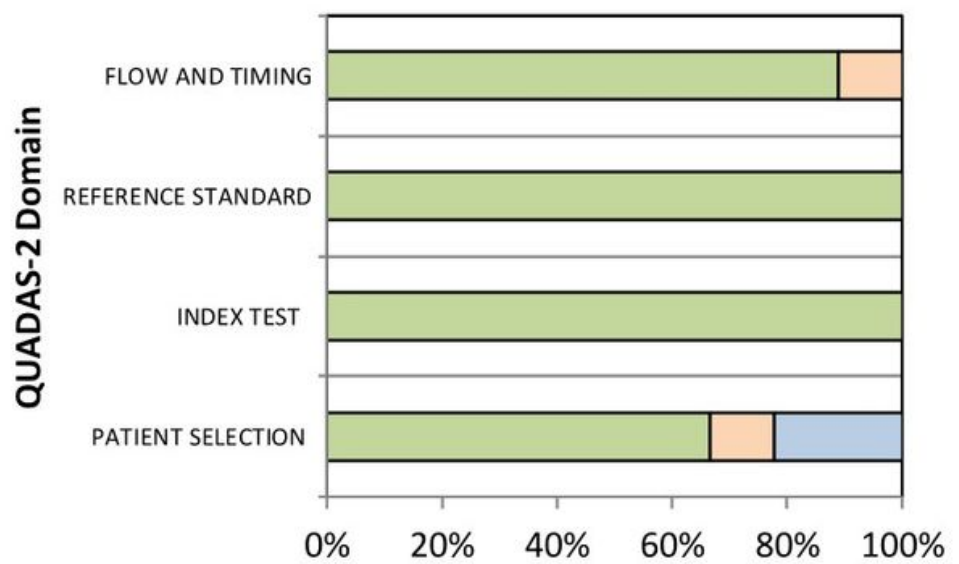

Proportion of studies with low, high or unclear

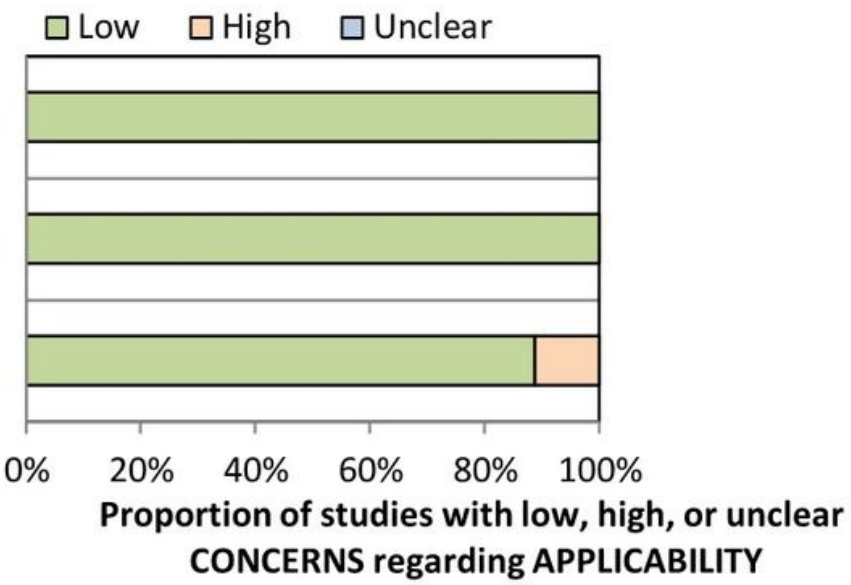




\section{Figure 2}

Methodological quality of the included studies using QUADAS-2 tool.
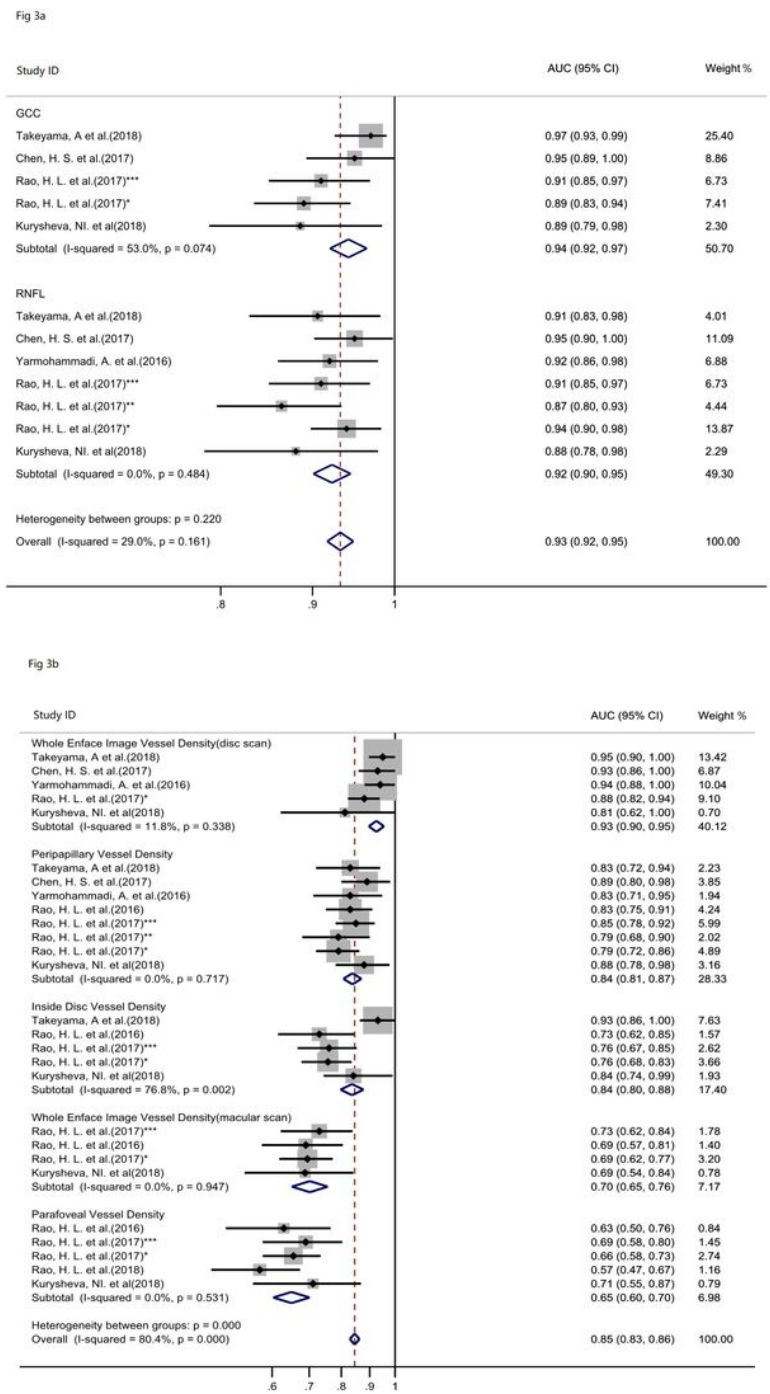

\section{Figure 3}

Diagnostic Accuracy of structural and vascular parameters in all glaucoma patients. Diagnostic Accuracy of OCT parameters . Diagnostic Accuracy of OCTA parameters. *: Rao HL, Pradhan ZS, Weinreb RN, et al. Optical Coherence Tomography Angiography Vessel Density Measurements in Eyes With Primary Open-Angle Glaucoma and Disc Hemorrhage. Journal of glaucoma 2017; 26:888-895. **: Rao HL, Kadambi SV, Weinreb RN, et al. Diagnostic ability of peripapillary vessel density measurements of optical coherence tomography angiography in primary open-angle and angle-closure glaucoma. The British journal of ophthalmology 2017; 101:1066-1070. ***: Rao HL, Pradhan ZS, Weinreb RN, et al. Vessel Density and Structural Measurements of Optical Coherence Tomography in Primary Angle Closure and Primary Angle Closure Glaucoma. American journal of ophthalmology 2017; 177:106-115. 


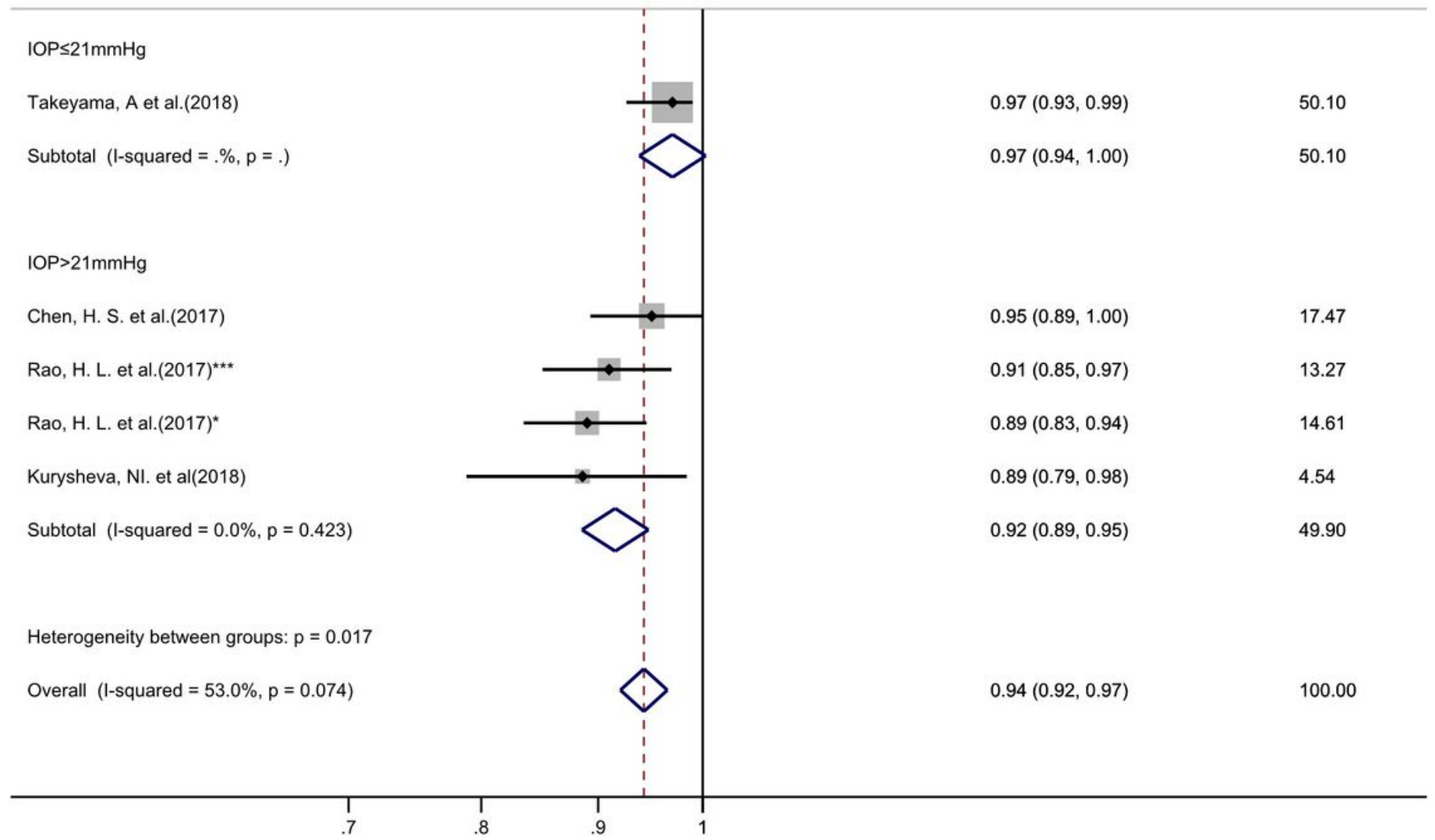

\section{Figure 4}

Diagnostic Accuracy of Ganglion Cell Complex for glaucoma patients in subgroup analysis. *: Rao HL, Pradhan ZS, Weinreb RN, et al. Optical Coherence Tomography Angiography Vessel Density Measurements in Eyes With Primary Open-Angle Glaucoma and Disc Hemorrhage. Journal of glaucoma 2017; 26:888-895. ***: Rao HL, Pradhan ZS, Weinreb RN, et al. Vessel Density and Structural Measurements of Optical Coherence Tomography in Primary Angle Closure and Primary Angle Closure Glaucoma. American journal of ophthalmology 2017; 177:106-115. 


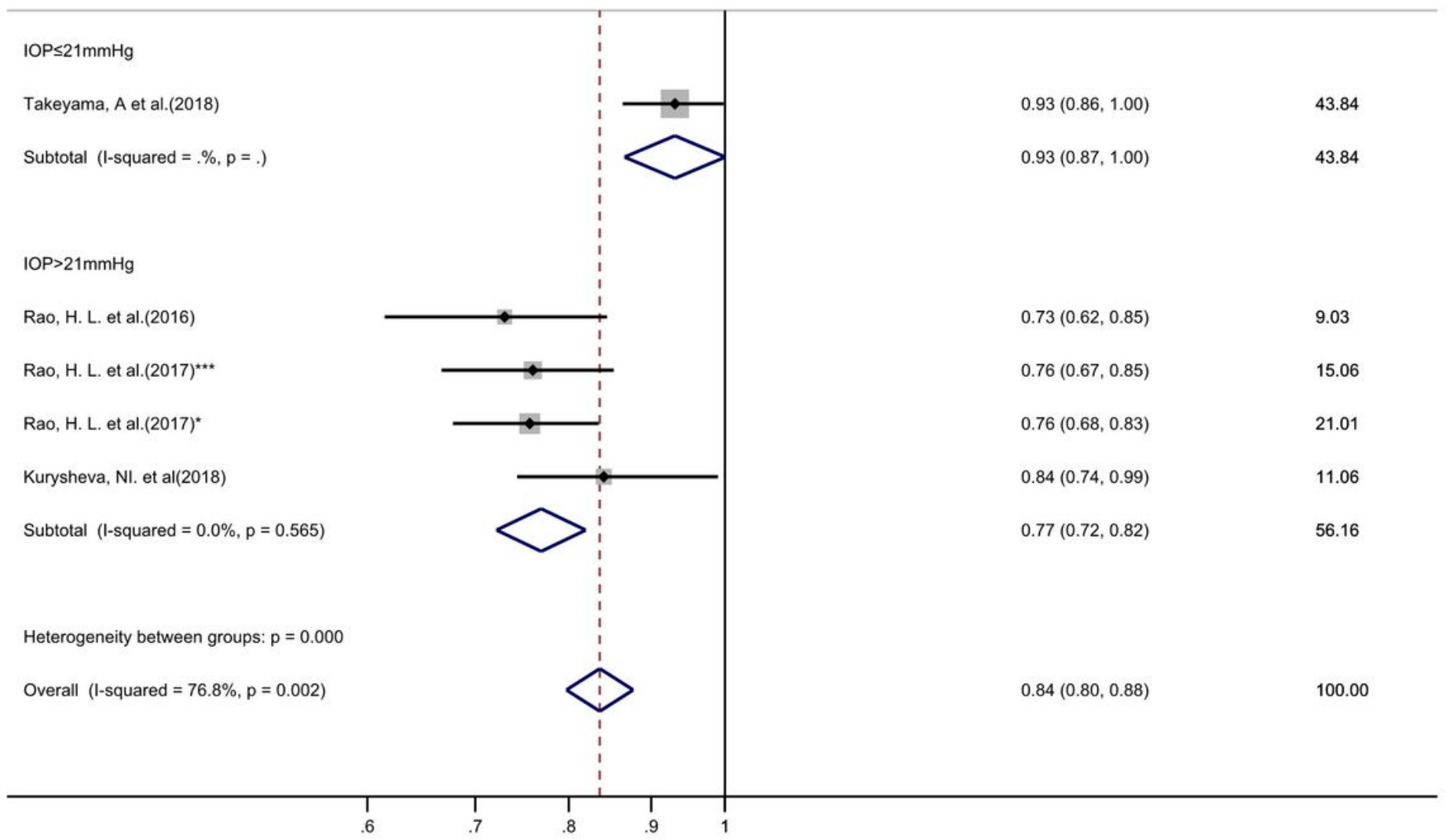

\section{Figure 5}

Diagnostic Accuracy of Inside Disc Vessel Density for glaucoma patients in subgroup analysis. *: Rao HL, Pradhan ZS, Weinreb RN, et al. Optical Coherence Tomography Angiography Vessel Density Measurements in Eyes With Primary Open-Angle Glaucoma and Disc Hemorrhage. Journal of glaucoma 2017; 26:888-895. **: Rao HL, Kadambi SV, Weinreb RN, et al. Diagnostic ability of peripapillary vessel density measurements of optical coherence tomography angiography in primary open-angle and angle-closure glaucoma. The British journal of ophthalmology 2017; 101:1066-1070. ***: Rao HL, Pradhan ZS, Weinreb RN, et al. Vessel Density and Structural Measurements of Optical Coherence Tomography in Primary Angle Closure and Primary Angle Closure Glaucoma. American journal of ophthalmology 2017; 177:106-115.

\section{Supplementary Files}

This is a list of supplementary files associated with this preprint. Click to download.

- additionalfile2.docx 